\title{
Prospective Application of Response Surface Methodology for Predicting High-Energy Mixing Process Conditions towards Fine Powders Flow Improvement
}

\author{
Karolina Leś ${ }^{\prime *}$, Ireneusz Opaliński ${ }^{1}$ \\ 1 Department of Chemical and Process Engineering, Rzeszow University of Technology, \\ al. Powstancow Warszawy 6, 35-959 Rzeszow, Poland \\ * Corresponding author's email: ichkl@prz.edu.pl
}

\begin{abstract}
Planetary ball mill was proposed as an intensive high-energy mixer to obtain flowability improvement of industrially exploited, cohesive and finely comminuted powders via dry coating. Response surface methodology (RSM) coupled with central composite rotatable design (CCRD) was applied as an effective method for the prediction of high-energy mixing conditions. The use of this procedure allows identifying relatively narrow ranges of high-energy mixing parameters (rotating speed of planetary ball mill and mixing time) and the amount of additives used (nanosilica and isopropyl alcohol) providing substantial improvement of the flowability of Aluminium hydroxide (Apyral) and Calcium carbonate powders. In order to find the optimal values of the process parameters, enabling to obtain the lowest values of flowability indices (angle of repose, compressibility index), the desirability function approach was applied. The obtained results may be a basis for developing a general routine allowing mixing parameters to be successfully predicted regarding some physical properties of powders only with no experiments needed.
\end{abstract}

Keywords: dry coating; powder flowability; high-energy mixing; planetary ball mill; response surface methodology

\section{INTRODUCTION}

Fine powders are often a main feedstock in many process industries, especially those focused on pharmaceuticals, chemicals, food, pigments or plastics. High degree of comminution affects the product quality, for example, it improves bioavailability of drugs, strengthens stability of suspensions, creams and ointments, as well as enhances the taste and appearance of food products (i.e. chocolate). On the other hand, smaller size of particles has a negative influence on the flowability of powder bed, hence manufacturing efficiency, storage and content uniformity of mixtures [1].

Although the problem with powder flow is well known, it still remains unsolved. The existing methods of flowability improvement, although effective to a certain extent, have many disadvantages. Using, for example, lubricants and glidants as cohesive powder admixtures may be regarded as a method for flow improvement; however, there is still a problem with the agglomeration of additives [2].

In recent years, a high-energy mixing method has been proven as an effective way for improving the flowability of cohesive powders. This method connects doping with delivering some mechanical energy to the powder bed, which results in overall breaking the agglomerates and freeing flow of powders. The sufficient amount of mechanical energy can be generated in a high-energy mixing process to obtain the dry coating phenomenon. Dry mechanical coating is a process of microand nano-guest particles (additives) deposition on the surface of larger host particles resulting in reduced inter-particles forces. The desired result can be obtained in different types of devices 
(Mechanofusion devices, Hybridizer, Theta Composer, Magnetically assisted impaction coating device and Rotating fluidized bed coater) [3].

A planetary ball mill, applied so far mainly for milling and carrying out mechanochemical processes, has recently been proven to be an effective device to perform high-energy mixing. It was firstly used as a high-energy mixer by Sonoda et al. [4] to obtain better dissolution of flurbiprofen via dry coating. Moreover, this type of mill can be used on an industrial scale [5].

The aim of this study was to find the optimal conditions of high-energy mixing in a planetary ball mill as a method of flowability improvement of finely ground cohesive powders (aluminium hydroxide and calcium carbonate). This will be the basis for developing some practical guidelines concerning prediction of the proper mixing conditions for which the best flowability can be obtained and which are believed to be effective for most fine powders of industrial importance.

\section{MATERIALS AND METHOD}

\section{Materials}

Aluminium hydroxide, Apyral ${ }^{\circledR}$ 40CD (Nabaltec AG, Germany), is a non-toxic, halogen-free and flame-retardant filler in the polymers applied in the cable industry [6]. Regardless of the practical importance of Apyral, there is a serious problem with handling this material due to its cohesiveness and poor flowability. For optimisation procedure, some earlier results obtained for the Calcium carbonate powder (Chempur, Poland) was also included [7]. The physical properties and particle size distribution of both powders are given in Table 1.

Hydrophilic fumed silica, Aerosil $\AA^{\circledR 200}$ (Evonik, Germany), with specific surface area $200 \mathrm{~m}^{2} / \mathrm{g}$ and average particle size about $12 \mathrm{~nm}$ [8] was used as a guest particle source. Silica is a modifier that is most often used in the process of dry coating. Furthermore, Jiao and Chen [9] proved the synergistic influence of the silica and aluminium hydroxide addition on decreasing the flammability of ethylene vinyl acetate (EVA).

Isopropyl alcohol (Stanlab, Poland) was used as a process control agent (PCA), needed to avoid caking of fine powders during their mixing in a planetary ball mill. This alcohol is relatively rarely used as PCA; however, according to Gabbitas et al. [10], it turns out to be an effective anticaking agent in high-energy mixing processes.

\section{Equipment}

A Mono Pulverisette 6 planetary ball mill (Fritsch, Germany) was used to perform dry coating in a high-energy mixing process. This type of a mill consisted of a mixing chamber (volume: $500 \mathrm{~cm}^{3}$ ) filled with balls (diameter: $5 \mathrm{~mm}$ ), both made of zirconium oxide. The ball to powder weight ratio was 8:1. High impact energy of milling balls was generated by planet-like movement of working chamber.

The surface morphology of Apyral and Calcium carbonate particles was investigated using a scanning electron microscope (SEM), after being sputter coated with carbon in the Institute of High Pressure Physics of the Polish Academy of Science.

Particle size distribution of both examined powders was measured after $60 \mathrm{~s}$ of ultrasonication in isopropyl alcohol as a dispersant using a Mastersizer 2000E (Malvern Panalytical, United Kingdom) particle size analyser.

\section{Flowability measurement}

The powder flowability improvement was evaluated by the Carr indices such as an angle of repose and compressibility index $(C I)$ calculated according to Eq. 1, where $\rho_{\mathrm{a}}$ is aerated bulk density and $\rho_{\mathrm{t}}$ is tapped density. The flowability indices were measured using Powder Characteristic Tester PT-S (Hosokawa Micron, Japan) [11].

$$
C I=\frac{\rho_{t}-\rho_{a}}{\rho_{t}} \cdot 100 \%
$$

Table 1. Particle size distribution and physical properties of unmodified Apyral and Calcium carbonate powders

\begin{tabular}{|l|c|c|c|c|c|c|c|}
\hline \multicolumn{1}{|c|}{ Material } & $\begin{array}{c}\mathrm{d}_{50}, \\
\mu \mathrm{m}\end{array}$ & $\begin{array}{c}\mathrm{d}_{10}, \\
\mu \mathrm{m}\end{array}$ & $\begin{array}{c}\mathrm{d}_{90}, \\
\mu \mathrm{m}\end{array}$ & $\begin{array}{c}\text { Angle of repose, } \\
\mathrm{deg}\end{array}$ & $\begin{array}{c}\text { Aerated bulk } \\
\text { density, } \mathrm{kg} / \mathrm{m}^{3}\end{array}$ & $\begin{array}{c}\text { Packed bulk } \\
\text { density, kg/m }\end{array}$ & $\begin{array}{c}\text { Compressibility } \\
\text { index, } \%\end{array}$ \\
\hline Apyral & 2.398 & 1.332 & 4.742 & 52 & 330 & 701 & 53 \\
\hline Calcium carbonate & 2.147 & 0.775 & 4.453 & 55 & 433 & 827 \\
\hline
\end{tabular}




\section{Design of experiments}

High-energy mixing in a planetary ball mill is a multi-parametric process. For that reason, to accomplish the experiment and to obtain the results needed for optimisation procedure, the Design of Experiment and Response Surface Methodology were applied. The arrangement of all conducted experiments was founded on Central Composite Rotatable Design and a second-order polynomial equation with interactions (Eq. 2). This equation was fitted to the experimental data to obtain the response functions for the angle of repose and the compressibility index [12].

$$
\begin{aligned}
& y=\left(b_{0}+\varepsilon\right)+\sum_{i=1}^{k} b_{i} x_{i}+ \\
& +\sum_{1 \leq i \leq j}^{k} b_{i j} x_{i} x_{j}+\sum_{i=1}^{k} b_{i i} x_{i i}^{2}
\end{aligned}
$$

where: $b_{0}$ is the constant term,

$\varepsilon$ is a residual associated with the experiments,

$x$ is a process variable,

$k$ is a number of input variables.

On the basis of the pre-experiments performed earlier, four main variables influenced the process: mixing speed, mixing time, amount of Aerosil as an admixture and amount of isopropyl alcohol as the PCA were selected. The actual value ranges of input variables were determined in such a way to make a successful performance of the experiment possible. All variables were analysed on five coded levels corresponding to their actual values according to Table 2 .

Central Composite Rotatable Design created for four process factors consists of 32 tests, including 17 standard factorial tests, 8 tests at a distance $\alpha$ from the centre of experiment (in star points) to obtain quadratic terms (star value in case of four process factors is $\alpha=2$ ) and 7 replications in the centre of the experiment. The experimental design matrix for coded levels of process variables with experimental values of the responses is given in Table 3.

Creation of proper experiment design, statistical analysis of response functions (ANOVA Analysis of Variance) and process optimisation were performed using the Statistica 12 software package (StatSoft).

\section{RESULTS}

\section{Statistical analysis}

The influence of mixing speed, mixing time, the amount of Aerosil and the amount of isopropyl alcohol on the angle of repose and compressibility index values were presented using second-order regression models with interactions. The significant response function created for coded levels of variables (after removing not significant coefficients) for angle of repose is as follows:

$$
\begin{gathered}
y_{1}=43.563-0.637 x_{1}-0.896 x_{2}- \\
-0.654 x_{3}+0.371 x_{2}^{2}-0.203 x_{3}^{2}+ \\
+0.206 x_{1} x_{3}-0.231 x_{1} x_{4}
\end{gathered}
$$

and for compressibility index:

$$
\begin{gathered}
y_{2}=47.163-0.721 x_{1}-0.821 x_{2}- \\
-0.787 x_{3}+0.204 x_{4}-0.620 x_{1}^{2}+0.392 x_{2}^{2}- \\
-0.320 x_{3}^{2}+0.294 x_{2} x_{3}
\end{gathered}
$$

The same models for actual levels of variables are, respectively:

$$
\begin{gathered}
y_{1}=59.6-0.0578 z_{1}-0.688 z_{2}-0.539 z_{3}+ \\
+0.0232 z_{2}^{2}-0.814 z_{3}^{2}+0.0137 z_{1} z_{3}+0.0219 z_{1} z_{4} \\
y_{2}=13.3+0.307 z_{1}-1.06 z_{2}+3.36 z_{3}+4.08 z_{4}- \\
-6.89 \cdot 10^{-4} z_{1}^{2}+0.0245 z_{2}^{2}-1.28 z_{3}^{2}+0.147 z_{2} z_{3}
\end{gathered}
$$

\begin{tabular}{|c|c|c|c|c|c|c|c|}
\hline \multirow{2}{*}{ Variable } & \multicolumn{2}{|c|}{ Symbol } & \multirow{2}{*}{$-\alpha$} & \multirow{2}{*}{-1} & \multirow{2}{*}{0} & \multirow{2}{*}{+1} & \multirow{2}{*}{$+\alpha$} \\
\hline & coded & actual & & & & & \\
\hline Mixing speed, rpm & $\mathrm{x}_{1}$ & $\mathrm{z}_{1}$ & 180 & 210 & 240 & 270 & 300 \\
\hline Mixing time, min & $\mathrm{x}_{2}$ & $\mathrm{z}_{2}$ & 2 & 6 & 10 & 14 & 18 \\
\hline Amount of Aerosil, mass fraction, $\%$ & $x_{3}$ & $\mathrm{z}_{3}$ & 1.5 & 2.0 & 2.5 & 3.0 & 3.5 \\
\hline Amount of isopropyl alcohol, $\mathrm{ml}$ & $\mathrm{x}_{4}$ & $\mathrm{z}_{4}$ & 0.90 & 0.95 & 1.00 & 1.05 & 1.10 \\
\hline
\end{tabular}

The Analysis of Variance (ANOVA) confirmed a significant influence of all process variables on the responses (angle of repose, compressibility index) in the experimental values

Table 2. Levels of input variables 
Table 3. Experimental design matrix and responses

\begin{tabular}{|c|c|c|c|c|c|c|c|}
\hline \multirow{3}{*}{$\begin{array}{c}\text { Group of } \\
\text { tests }\end{array}$} & \multirow{3}{*}{$\begin{array}{c}\text { Test } \\
\text { number }\end{array}$} & \multicolumn{4}{|c|}{ Coded levels of variables } & \multicolumn{2}{|c|}{ Output variables } \\
\hline & & Mixing speed & Mixing time & $\begin{array}{c}\text { Amount of } \\
\text { Aerosil }\end{array}$ & $\begin{array}{l}\text { Amount of } \\
\text { propan-2-ol }\end{array}$ & Angle of repose & $\begin{array}{c}\text { Compressibility } \\
\text { index }\end{array}$ \\
\hline & & $\mathrm{x}_{1}$ & $x_{2}$ & $\mathrm{x}_{3}$ & $\mathrm{x}_{4}$ & $\begin{array}{c}\mathrm{y}_{1} \\
\mathrm{deg}\end{array}$ & $\begin{array}{l}\mathrm{y}_{2} \\
\%\end{array}$ \\
\hline \multirow{16}{*}{ 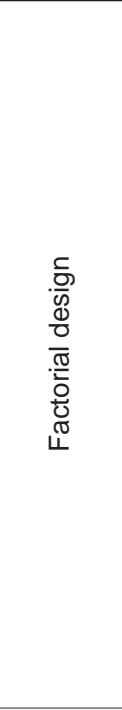 } & 1 & -1 & -1 & -1 & -1 & 45.6 & 48.6 \\
\hline & 2 & -1 & -1 & -1 & 1 & 46.2 & 49.5 \\
\hline & 3 & -1 & -1 & 1 & -1 & 43.9 & 45.9 \\
\hline & 4 & -1 & -1 & 1 & 1 & 44.4 & 46.9 \\
\hline & 5 & -1 & 1 & -1 & -1 & 44.1 & 47.1 \\
\hline & 6 & -1 & 1 & -1 & 1 & 44.4 & 47.3 \\
\hline & 7 & -1 & 1 & 1 & -1 & 42.4 & 45.9 \\
\hline & 8 & -1 & 1 & 1 & 1 & 42.7 & 46.1 \\
\hline & 9 & 1 & -1 & -1 & -1 & 44.6 & 47.6 \\
\hline & 10 & 1 & -1 & -1 & 1 & 43.9 & 47.7 \\
\hline & 11 & 1 & -1 & 1 & -1 & 43.2 & 45.5 \\
\hline & 12 & 1 & -1 & 1 & 1 & 43.2 & 45.7 \\
\hline & 13 & 1 & 1 & -1 & -1 & 43.1 & 45.6 \\
\hline & 14 & 1 & 1 & -1 & 1 & 42.2 & 45.7 \\
\hline & 15 & 1 & 1 & 1 & -1 & 42.1 & 44.5 \\
\hline & 16 & 1 & 1 & 1 & 1 & 41.7 & 44.5 \\
\hline \multirow{8}{*}{ 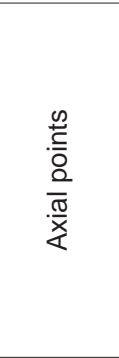 } & 17 & -2 & 0 & 0 & 0 & 45.3 & 46.6 \\
\hline & 18 & 2 & 0 & 0 & 0 & 42.5 & 43.2 \\
\hline & 19 & 0 & -2 & 0 & 0 & 47.6 & 51.2 \\
\hline & 20 & 0 & 2 & 0 & 0 & 43.0 & 46.7 \\
\hline & 21 & 0 & 0 & -2 & 0 & 44.3 & 47.3 \\
\hline & 22 & 0 & 0 & 2 & 0 & 41.7 & 44.9 \\
\hline & 23 & 0 & 0 & 0 & -2 & 43.3 & 46.5 \\
\hline & 24 & 0 & 0 & 0 & 2 & 44.0 & 47.6 \\
\hline \multirow{7}{*}{ 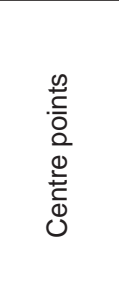 } & 25 & 0 & 0 & 0 & 0 & 43.3 & 47.0 \\
\hline & 26 & 0 & 0 & 0 & 0 & 43.3 & 46.7 \\
\hline & 27 & 0 & 0 & 0 & 0 & 43.8 & 47.1 \\
\hline & 28 & 0 & 0 & 0 & 0 & 44.0 & 47.8 \\
\hline & 29 & 0 & 0 & 0 & 0 & 43.7 & 47.5 \\
\hline & 30 & 0 & 0 & 0 & 0 & 43.4 & 47.4 \\
\hline & 31 & 0 & 0 & 0 & 0 & 43.6 & 47.3 \\
\hline
\end{tabular}

range and lack of fit test verified the created models fitting accuracy (probability value $p>0.05$ ).

The experimental and calculated values of angle of repose and compressibility index were in a very good agreement, as validated by correlation coefficient values $\left(R^{2}\right)$, which are 0.95 and 0.94 , respectively (Fig. 1).

The effect of process conditions (mixing speed and time) and the amount of the additives (Aerosil, isopropyl alcohol) on the powder flowability can be presented on 3-D response surface plots, as shown in Figure 2 and Figure 3.

Similar response functions, representing the influence of mixing speed and time, as well as the amounts of Aerosil and isopropyl alcohol on the angle of repose and the compressibility index values for finely ground Calcium carbonate powder, were obtained earlier [7] and for coded levels of variables they are as follows:

$$
\begin{gathered}
y_{1}=41.973-0.637 x_{1}-0.504 x_{2}-1.021 x_{3}+ \\
+0.587 x_{4}+0.427 x_{1}^{2}+0.264 x_{2}^{2}+0.539 x_{3}^{2}+ \\
+0.256 x_{1} x_{2}+0.306 x_{1} x_{3}+0.269 x_{2} x_{3}+ \\
+0.206 x_{2} x_{4}-0.244 x_{3} x_{4} \\
y_{2}=45.608-0.962 x_{1}-1.079 x_{2}- \\
-1.037 x_{3}+0.562 x_{4}+0.223 x_{2}^{2}
\end{gathered}
$$

The response functions for both Apyral (Eqs. 3 and 4) and Calcium carbonate (Eqs. 7 and 8) completed in the way presented above will be used to find the optimal conditions of high-energy mixing 
a)

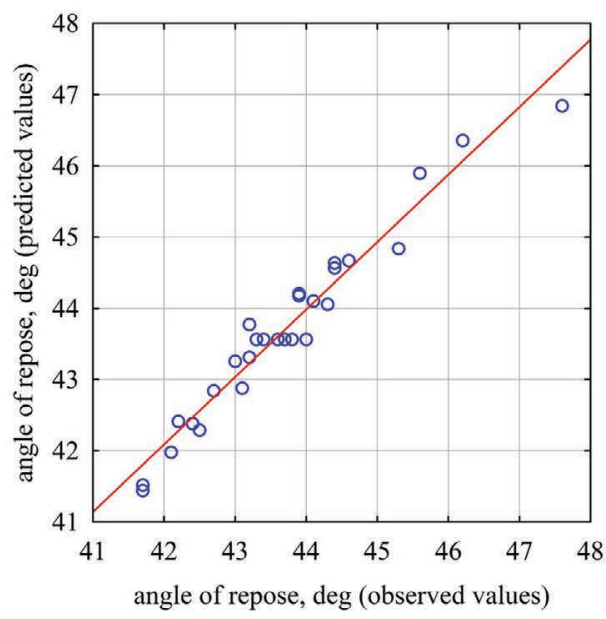

b)

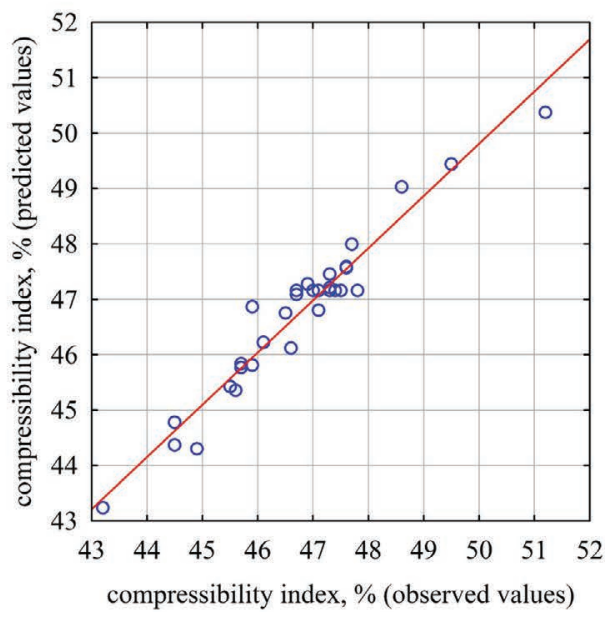

Fig. 1. Relation of experimental and predicted values of: a) angle of repose (according to Eq. 3); b) compressibility index (according to Eq. 4)
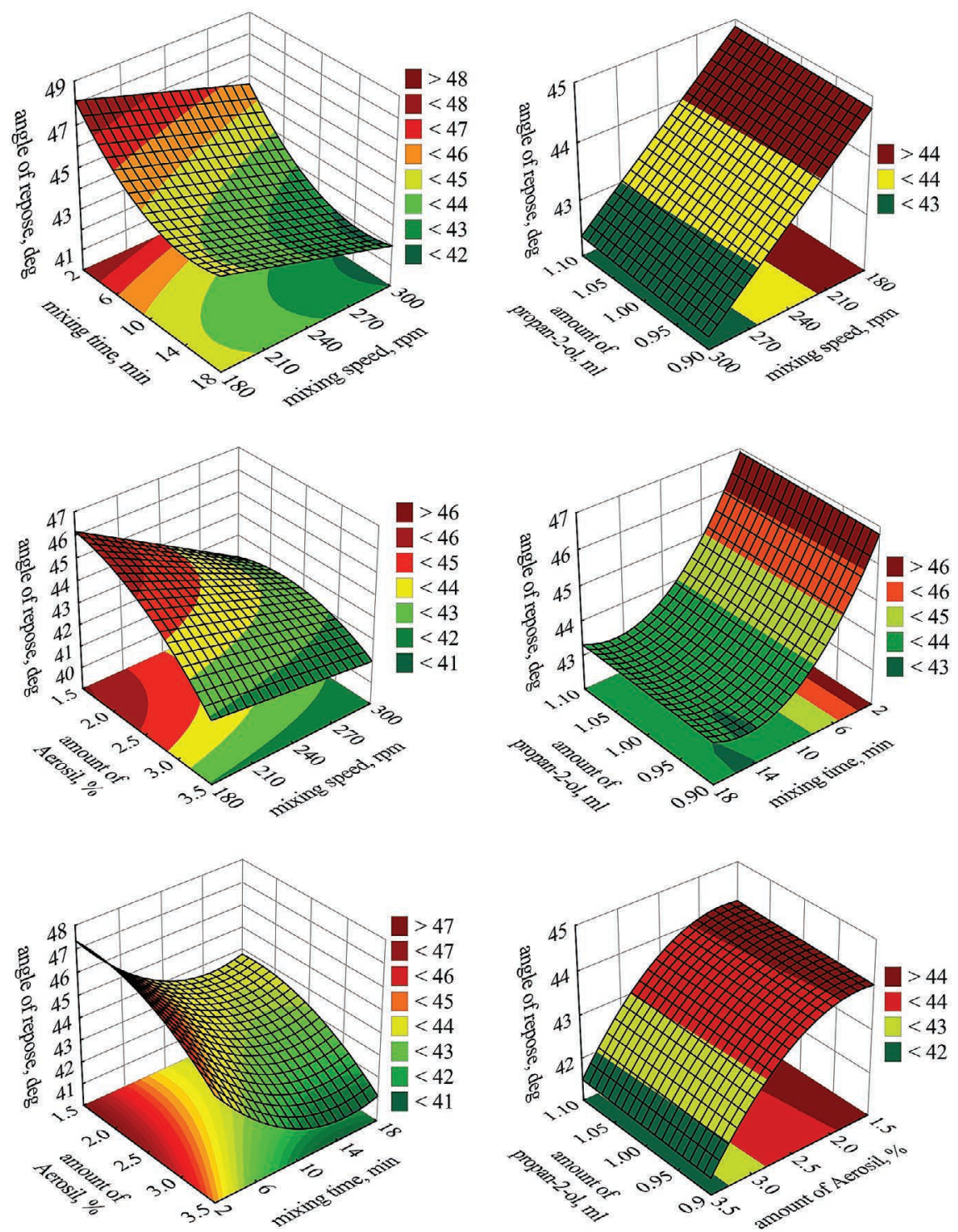

Fig. 2. The effect of process variables on angle of repose of Apyral (factors not shown on the plots are at the centre level) 

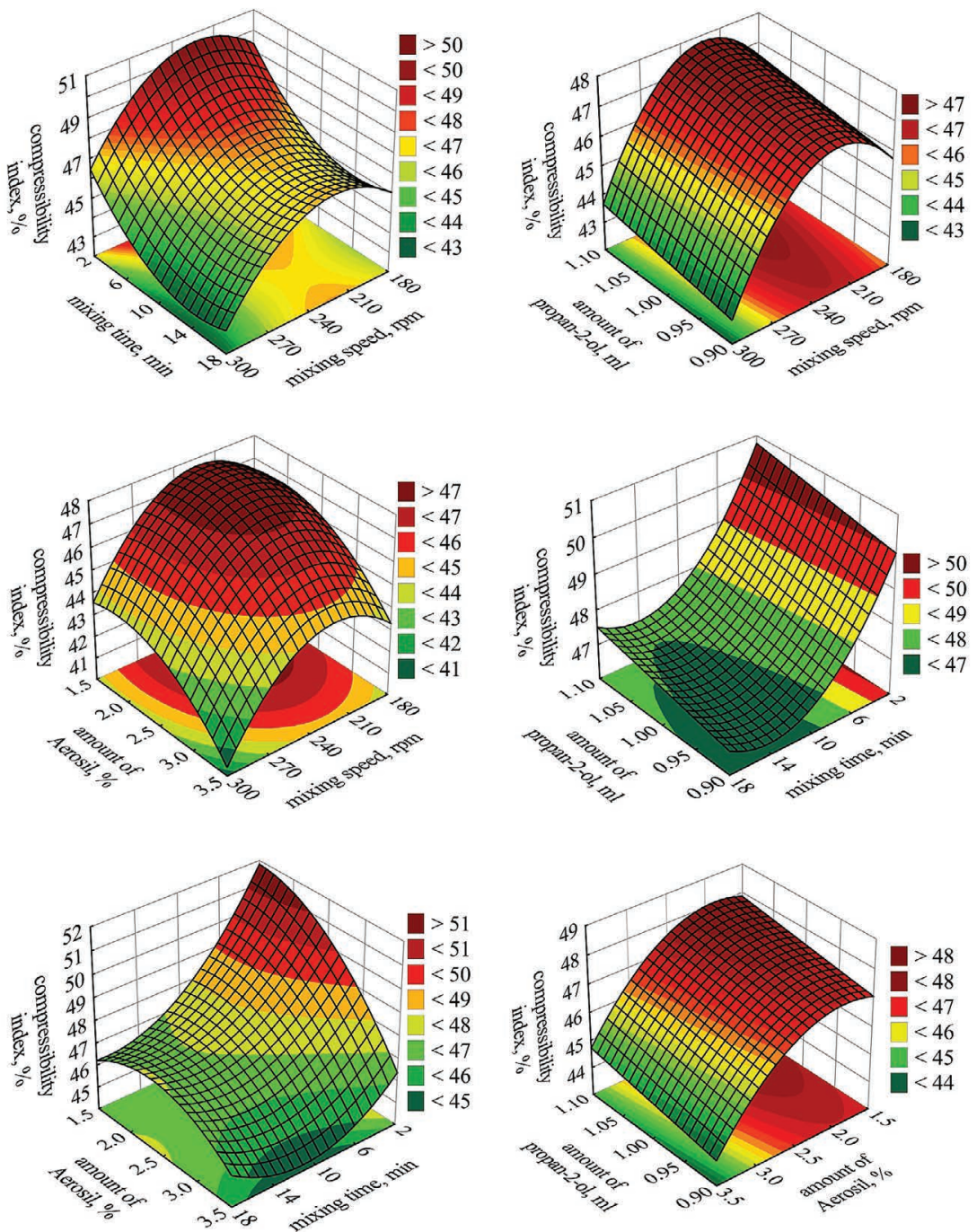

Fig. 3. The effect of process variables on compressibility index of Apyral (factors not shown on the plots are at the centre level)

as a method of flowability improvement for finely ground cohesive powders as given below.

\section{Process optimisation}

Multi-parametric process optimisation including two responses requires a procedure, which allows taking into account the simultaneous influence of changes of process parameters levels on both output variables values. Hence, to perform the process optimisation, all model equations will be converted to a desirability function $\left(f_{\mathrm{d}}\right)$, maximum value of which is attributed to the best level of powder flowability, i.e. the smallest values of the angle of repose and compressibility index. The first step of the desirability function approach is a transformation of the response functions created for both flowability indices to individual desirability functions $\left(f_{\mathrm{d}, \mathrm{j}}\right)$ with values ranging from 0 (undesirable responses) to 1 (the most desirable responses).

The goal of the proposed optimisation route is the maximisation of the overall desirability function, calculated as a geometric mean of individual desirability functions [13]:

$$
f_{d}=\sqrt{f_{d, i 1} \cdot f_{d, i 2}}
$$

and input variables values should be chosen between star values:

$$
-\alpha \leq x_{i} \leq+\alpha, i=1, \ldots, k
$$

where: $k$ - number of input variables.

The values of flowability indices of Apyral as well as of Calcium carbonate measured for unmodified powder were expected to be the least desirable (individual desirability function equal to 0). Furthermore, decreasing the angle 
of repose and compressibility index values was treated equivalently. Thus, the scope of flowability indices changes was assumed to be equal to 20 degrees and $20 \%$, respectively, and covered the overall range of experimental response values. The most desirable values were obtained after subtracting this value from the least desirable ones (individual desirability function equal to 0 ) and it was also assumed that the mid-values were changing in a linear way.

The desirability profiles for the angle of repose and compressibility index of Apyral and Calcium carbonate were presented in Fig. 4 d) and Fig. 5 d). On the basis of this data, the response functions (Eqs. 3, 4, 7, 8) were converted to individual desirability functions and then to overall desirability functions independently for each examined material. Considering non-linear nature of these functions and existence of local minimums, in order to optimise each desirability function, the grid nodes searching method was applied. In order to obtain the values of input variables in grid nodes, the overall values ranges were divided into intervals, as shown in Table 4.

The small number of nodes allowed for fast determination of the optimum values and the problem with optimum between grid nodes was solved by using real measurement points, for example for mixing speed the interval was $10 \mathrm{rpm}$, which was exactly the value of mill setting (the mixing speed had to be a multiple of $10 \mathrm{rpm}$ ).

In order to obtain the optimal process conditions, the overall desirability function (Eq. 9) with constraints (Eq. 10) was chosen as an objective function and optimisation in grid nodes was performed using the Statistica 12 software package. The results of the calculations are shown in
Table 5. In comparison, the corresponding values of both responses obtained experimentally and calculated on the basis of Eqs. 3, 4, 7, 8 are given in the same Table.

In Figure 4 and Figure 5, the effect of mixing speed, mixing time, the amounts of Aerosil and isopropyl alcohol on the angle of repose (a), compressibility index (b) and overall desirability function (c) are shown. The factors not shown on the plots are at optimal level values, according to those given in Table 5. One can observe that the highest values of desirability function (the lowest values of flowability indices) can be obtained for some range of input variables, because the unit change of the angle of repose or compressibility index values do not influence the powder flowability significantly.

For this reason, the scope of process variable values, for which the difference between flowability indices was lesser than a unit, was determined based on Fig. 4, Fig. 5. Table 6 presents the input variable values ranges needed to obtain the best powder flowability, while maintaining the remaining values at the levels assigned as optimal (according to Table 5).

\section{Surface morphology and particle size distribution}

In order to confirm that the process of dry coating of silica particles on the surface of Apyral and Calcium carbonate particles was achieved, a scanning electron microscope analysis was performed. The SEM micrographs of the host particles surface before and after modification are shown in Figure 6. As seen from the micrographs, the small Aerosil particles are regularly deposited

Table 4. Intervals number of input variables values in the grid nodes

\begin{tabular}{|c|c|c|c|c|c|c|}
\hline \multicolumn{3}{|c|}{ Input variable } & $\begin{array}{c}\text { Mixing } \\
\text { speed, rpm }\end{array}$ & $\begin{array}{c}\text { Mixing } \\
\text { time, min }\end{array}$ & $\begin{array}{l}\text { Amount of aerosil, } \\
\text { mass fraction, } \%\end{array}$ & $\begin{array}{c}\text { Amount of } \\
\text { propan-2-ol, ml }\end{array}$ \\
\hline & Material & step & 10 & 1 & 0.1 & 0.05 \\
\hline \multirow{2}{*}{$\begin{array}{l}\text { Intervals } \\
\text { number }\end{array}$} & Apyral & & 12 & 16 & 20 & 4 \\
\hline & Calcium carbonate & & 16 & 16 & 20 & 20 \\
\hline
\end{tabular}

Table 5. Optimal conditions of high-energy mixing for Apyral and Calcium carbonate

\begin{tabular}{|c|c|c|c|c|c|c|c|c|c|c|c|c|}
\hline \multirow{2}{*}{ Material } & \multirow{2}{*}{$\begin{array}{l}\text { Mixing } \\
\text { speed, } \\
\text { rpm }\end{array}$} & \multirow{2}{*}{$\begin{array}{l}\text { Mixing } \\
\text { time, } \\
\text { min }\end{array}$} & \multirow{2}{*}{$\begin{array}{c}\text { Amount of } \\
\text { aerosil, } \\
\text { mass } \\
\text { fraction, } \%\end{array}$} & \multirow{2}{*}{$\begin{array}{c}\text { Amount of } \\
\text { isopropyl } \\
\text { alcohol, } \\
\text { ml }\end{array}$} & \multicolumn{4}{|c|}{$\begin{array}{c}\text { Angle of repose, } \\
\text { deg }\end{array}$} & \multicolumn{4}{|c|}{$\begin{array}{c}\text { Compressibility index, } \\
\%\end{array}$} \\
\hline & & & & & $\begin{array}{l}\text { calcu- } \\
\text { lated }\end{array}$ & $\begin{array}{l}\text { experi- } \\
\text { mental }\end{array}$ & $\begin{array}{c}\text { absolute } \\
\text { error }\end{array}$ & $\begin{array}{l}\text { relative } \\
\text { error, } \%\end{array}$ & \begin{tabular}{l|} 
calcu- \\
lated \\
\end{tabular} & $\begin{array}{l}\text { experi- } \\
\text { mental }\end{array}$ & \begin{tabular}{|c|}
$\begin{array}{c}\text { absolute } \\
\text { error }\end{array}$ \\
\end{tabular} & $\begin{array}{l}\text { relative } \\
\text { error, } \%\end{array}$ \\
\hline Apyral & 300 & 13 & 3.0 & 1.1 & 39.6 & 41.3 & 1.7 & 4.3 & 40.8 & 43.3 & 2.5 & 6.1 \\
\hline $\begin{array}{l}\text { Calcium } \\
\text { carbonate }\end{array}$ & 350 & 16 & 2.6 & 0.5 & 42.1 & 41.1 & 1.0 & 2.4 & 40.4 & 43.5 & 3.1 & 7.7 \\
\hline
\end{tabular}




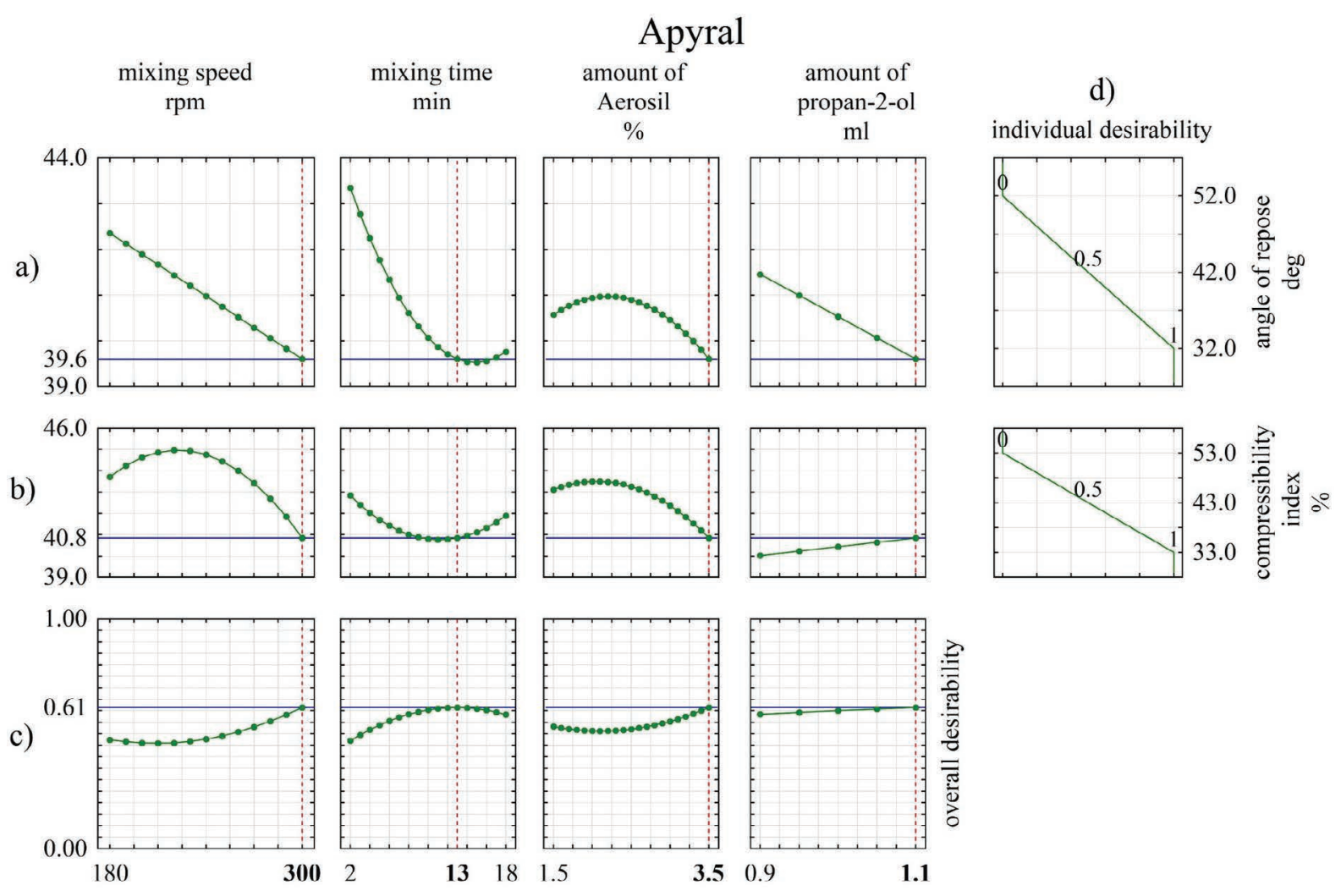

Fig. 4. Profiles of predicted responses values and desirability function for Apyral

a)
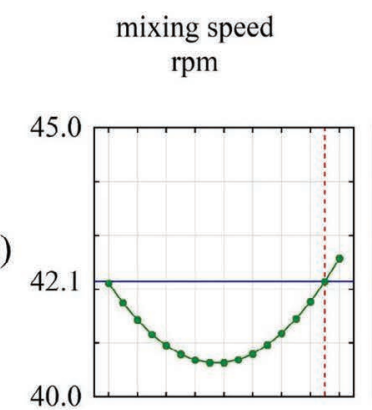

b)
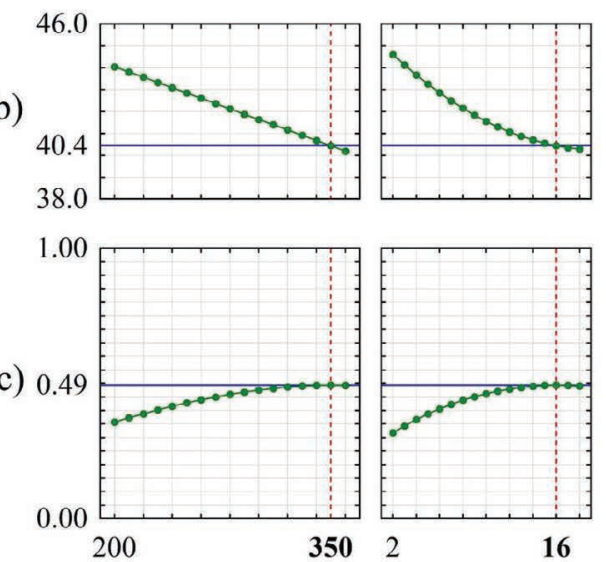

\section{Calcium carbonate}

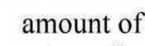

Aerosil

$\%$
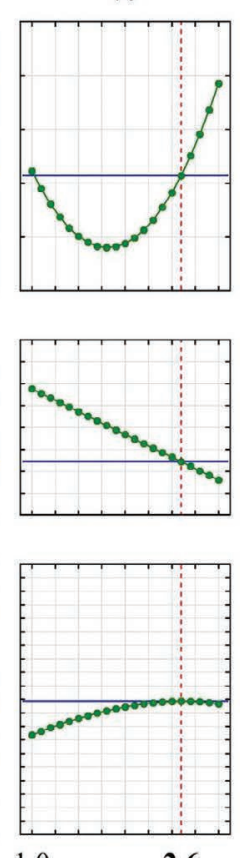

1.0 amount of propan-2-ol $\mathrm{ml}$
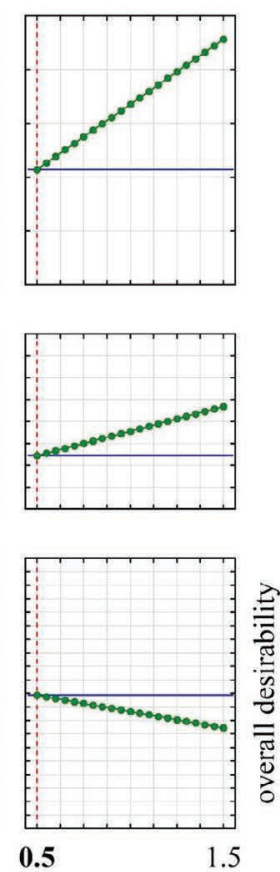

d)

individual desirability
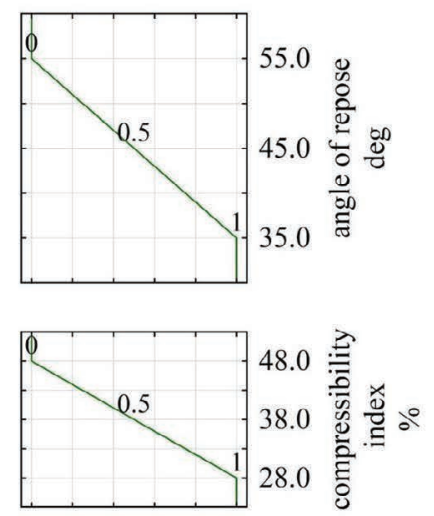

Fig. 5. Profiles of predicted responses values and desirability function for Calcium carbonate 
Table 6. The values of input variables needed to obtain the best flowability in high-energy mixing process

\begin{tabular}{|l|c|c|c|c|}
\hline $\begin{array}{c}\text { Variable, values } \\
\text { range }\end{array}$ & $\begin{array}{c}\text { Mixing speed, } \\
\text { rpm }\end{array}$ & $\begin{array}{c}\text { Mixing time, } \\
\text { min }\end{array}$ & $\begin{array}{c}\text { Amount of Aerosil, } \\
\text { mass fraction, \% }\end{array}$ & $\begin{array}{c}\text { Amount of isopropyl } \\
\text { alcohol, ml }\end{array}$ \\
\hline Material & $280-300$ & $6-18$ & $1.5-3.0$ & $0.5-1.5$ \\
\hline Calcium carbonate & $270-360$ & $10-18$ & $1.7-3.0$ & $0.5-0.9$ \\
\hline
\end{tabular}
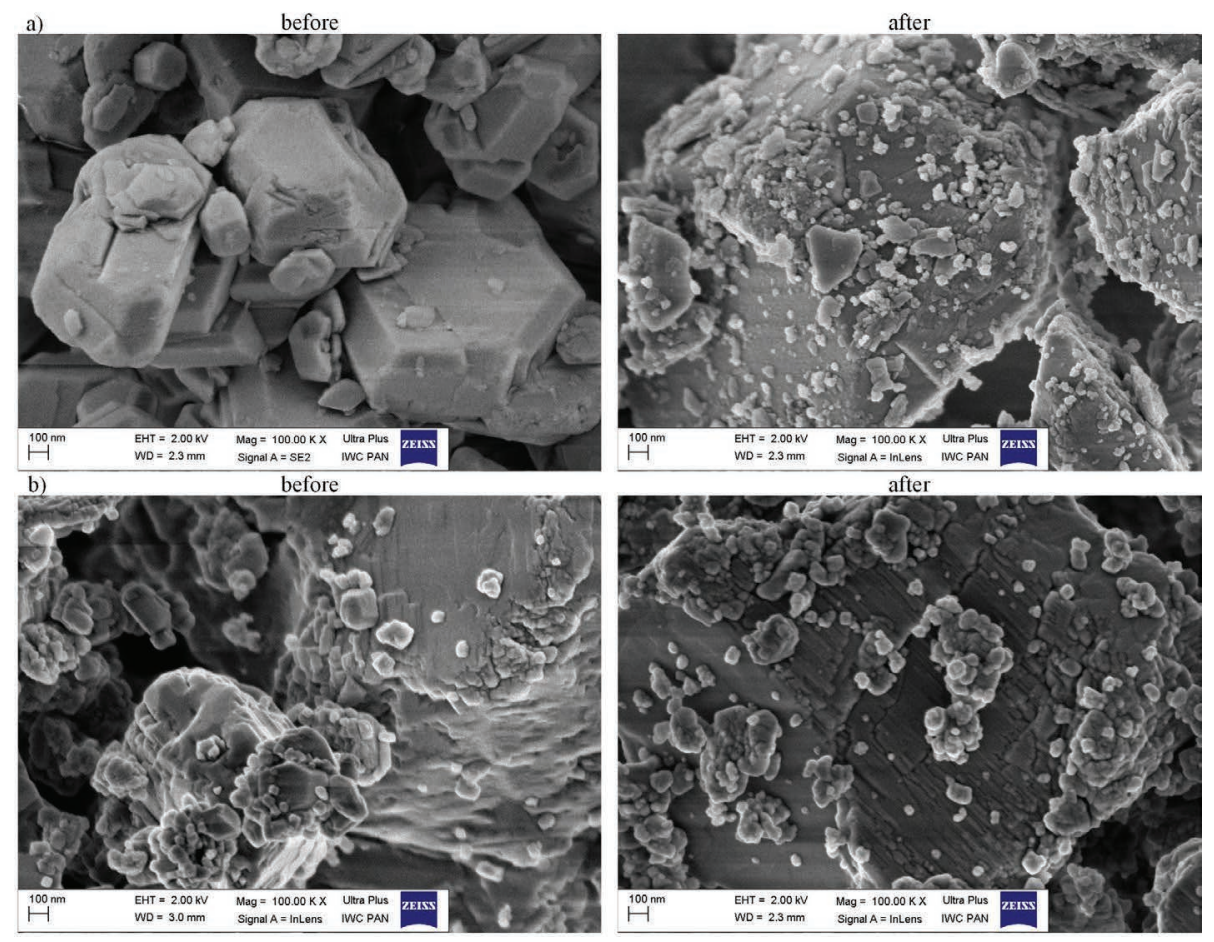

Fig. 6. SEM images of particles before and after high-energy mixing: a) Apyral; b) Calcium carbonate

on the surface of larger host particles and this clearly proves that dry coating phenomenon is a result of high-energy mixing process proceeding in a planetary ball mill.

\section{CONCLUSIONS}

- High-energy mixing is an effective method for the accomplishment of the dry coating process resulting in a considerable improvement of the cohesive powder flow indices; for finely ground Apyral there was a significant decrease of both angle of repose (from 52 to $41 \mathrm{deg}$ ) and compressibility index value (from 53 to $43 \%$ ). Similar advantageous results concern other highly cohesive powder like Calcium carbonate.

- Design of Experiments and Response Surface Methodology are useful tools to find the optimal conditions for planning multi-parameters process like high-energy mixing of cohesive powders. Using the desirability function and optimisation in grid nodes, it is possible to predict relatively narrow process parameter ranges providing the desired quality of powder mixtures flow. These parameters ranges include mixing speed: 280-300 rpm and mixing time: 6-18 min for Apyral and 270-360 rpm and 10-18 min for Calcium carbonate, respectively.

- The results obtained allow determining some practical guidelines for predicting the proper high-energy mixing parameter values and the amount of additives used, which are believed to be effective in flowability improvement of most highly cohesive powders.

- The scanning electron microscope analysis confirmed that dry particle coating phenomenon occurred as a result of intensive powder particles mixing in the planetary ball mill. 


\section{REFERENCES}

1. Prescott J.K., Barnum R.A. On power flowability. Pharmaceutical Technology. 2000;24(10):60-84.

2. Zhou Q., Qu L., Larson I., Stewart P.J., Morton D.A.V. Effect of mechanical dry particle coating on the improvement of powder flowability for lactose monohydrate: A model cohesive pharmaceutical powder. Powder Technology. 2011; 207(1-3): 414-21.

3. Pfeffer R., Dave R.N., Wei D., Ramlakhan M. Synthesis of engineered particulates with tailored properties using dry particle coating. Powder Technology. 2001;117(1-2):40-67.

4. Sonoda R., Horibe M., Oshima T., Iwasaki T., Watano S. Improvement of dissolution property of poorly water-soluble drug by novel dry coating method using planetary ball mill. Chemical and Pharmaceutical Bulletin (Tokyo). 2008;56(9):1243-7.

5. Fokina E.L., Budim N.I., Kochnev V.G., Chernik G.G. Planetary mills of periodic and continuous action. Journal of Material Science. 2004;39(16/17):5217-21.

6. Perthué A., Bussière P.-O., Baba M., Larche J.-F., Therias S., Karasu F., Croutxé-Barghorn C. Impact of particle size in PE/ATH composites: The relationship between the interphase and water uptake. Progress in Organic Coatings. 2018;114:145-53.

7. Leś K., Kowalski K., Opaliński I. Optimisation of process parameters in high energy mixing as a method of cohesive powder flowability improvement. Chemical and Process Engineering - Inżynieria Chemiczna i Procesowa. 2015;36(4):449-60.

8. Evonik Resource Efficiency, Gmbh. AEROSIL $®$ 200 Hydrophilic fumed silica. 2018.

9. Jiao C.-M., Chen X.-L. Influence of fumed silica on the flame-retardant properties of ethylene vinyl acetate/aluminum hydroxide composites. Journal of Applied Polymer Science. 2011;120(3):1285-9.

10. Gabbitas B., Cao P., Raynova S., Zhang D. Microstructural evolution during mechanical milling of $\mathrm{Ti} / \mathrm{Al}$ powder mixture and production of intermetallic TiAl cathode target. Journal of Material Science. 2012;47(3):1234-43.

11. Jallo L.J., Ghoroi C., Gurumurthy L., Patel U., Davé R.N. Improvement of flow and bulk density of pharmaceutical powders using surface modification. International Journal of Pharmaceutics. 2012;423(2):213-25.

12. Aslan N. Application of response surface methodology and central composite rotatable design for modeling and optimization of a multi-gravity separator for chromite concentration. Powder Technology. 2008;185(1):80-6.

13. StatSoft I. Big Data, Data Mining, Predictive Analytics, Statistics, StatSoft Electronic Textbook. Electronic Statistics Textbook. 2013. http://www. statsoft.com/textbook (accessed May 23, 2019) 